Marcos Honori Quaglio $^{(a)}$, Adriana Sperandio Ventura Pereira de Castro $^{(\mathrm{b})}$,Alexsandro dos Santos Rodrigues ${ }^{(\mathrm{c})}$, Neri Rodrigues Contin ${ }^{(\mathrm{d})}$

(a) Universidade Federal de Juiz de Fora, MG, Brasil / marcos.quaglio@engenharia.ufjf.br

(b) CES-JF/PUCMINAS, MG, Brasil / adrianaventura@ pucminas.cesjf.br

(c)Universidade Federal de Juiz de Fora, MG, Brasil / alexsanrodri@ yahoo.com.br

(d)Universidade Federal de Juiz de Fora, MG, Brasil / nericontin@gmail.com

\title{
LIDERANÇA SITUACIONAL - UMA ABORDAGEM TEÓRICA A PARTIR DO MODELO DE HERSEY E BLANCHARD
}

\begin{abstract}
RESUMO
Este trabalho tem por objetivo trazer algumas concepções acerca do exercício da liderança situacional e de suas contribuições nas tomadas de decisão dentro das organizações, levando-se em conta a análise que o líder faz do perfil de cada colaborador e de sua equipe, em função do grau de maturidade de cada um deles, e as diversas situações enfrentadas nesse ambiente. Para isso foi realizada uma pesquisa bibliográfica dos principais autores da área e um enfoque no modelo de liderança situacional de Hersey e Blanchard. As reflexões e conclusões que se amparam nesse material teórico apontam para a necessidade de líderes cada vez mais eficazes, flexíveis e dinâmicos diante de tamanha volatilidade no mundo moderno, o que é fundamental para que as organizações continuem sobrevivendo e mantenham a competitividade em meio às situações apresentadas. A Liderança Situacional salienta a necessidade de os líderes adaptarem seus perfis de liderança para atuações cada vez mais eficazes aos distintos cenários no ambiente organizacional.
\end{abstract}

Palavras-chaves: Líder. Liderança Situacional. Tomada de Decisão. Ambiente Organizacional.

\section{SITUATIONAL LEADERSHIP - A THEORETICAL APPROACH FROM THE MODEL OF HERSEY AND BLANCHARD}

\begin{abstract}
This work has the objective to bring about conceptions regarding the exercise of situational leadership and its contributions in decision making within organizations, accounting for the analysis the leader makes about each collaborator in his/hers team as whole, as a function of their respective degree of maturity and the several situations faced in this environment. There has been done a biographical research about the main authors of the field and with emphasis on the Hersey e Blanchard's situational leadership model. The reasoning and conclusions presented in this theoretical material indicate the necessity of leaders ever more efficient, flexible and dynamic before such volatility of the modern world, which is fundamental for the organizations to keep functioning and maintain competitiveness among the presented situations. Situational leadership points out the necessity of leaders to adapt their leadership profile to efficient actions towards distinct scenarios found in organizational environment.
\end{abstract}

Keywords: Leader. Situational Leadership.Decision Making.OrganizationalEnvironment. 


\section{Introdução}

O presente trabalho aborda o tema da Liderança Situacional, um modelo de liderança altamente eficaz e cada vez mais presente nas organizações, com resultados bastante positivos tanto no aspecto das relações humanas como na produtividade dos colaboradores. É um modelo de liderança elaborado por Hersey e Blanchard, na década de 80 , e que permite ao líder tomar decisões com maior segurança e apoio por parte de toda a organização, decisões estas que consideram o nível de maturidade do colaborador e o ambiente de trabalho como essenciais para o sucesso da organização, propiciando ao líder exercer sua liderança adequando estilos de liderança diferentes conforme as situações encontradas.

Com o crescimento da economia mundial, particularmente a brasileira, houve uma grande demanda por cargos de liderança. O cenário atual é de constantes mudanças e incertezas e, dessa forma, é importante que os líderes desenvolvam novas habilidades, adaptando-se às tendências do mercado. $\mathrm{O}$ aumento da produtividade tem colocado toda a organização diante de novos desafios, tornando a gestão mais difícil e dinâmica, exigindo de todos os gestores uma atuação mais eficiente.

Para Rocha (2001, p.13),

Neste novo mercado, ganhos de produtividade, por exemplo, tornam-se fundamentais e a melhoria do desempenho dos recursos humanos por meio da capacitação é um fator crítico de sucesso, para isso as empresas têm realizado enormes e constantes investimentos no treinamento e desenvolvimento dos profissionais visando sua adequação às novas exigências empresariais e do mercado.

Os líderes acabam assumindo responsabilidades cada vez maiores e estratégicas frente às equipes, pois liderar implica fazer com que as equipes interajam e se desenvolvam; implica promover ajustes à estrutura da organização, planejar, influenciar no comportamento humano etc., sendo os resultados de suas tarefas, muitas vezes, sinalizadores do sucesso ou fracasso das organizações. Segundo Chiavenato (2000, p.23), “As empresas bem sucedidas são aquelas que conseguem adaptar-se adequadamente às demandas ambientais".

As organizações buscam cada vez mais por líderes que saibam trabalhar com poucos recursos e em curto espaço de tempo. Quanto maior a sua eficácia e maior o número de equipes otimizadas, melhores os resultados. Nessa conjuntura, frente às competições impostas pelo mercado, são uma questão de sobrevivência os processos decisórios, independente de as decisões estarem centradas na área operacional, tática ou estratégica. Andrade et al (2010, p.11) afirmam que "diante das incertezas desse cenário os líderes devem ser capazes de adotar novos modelos mentais, percebendo que as mudanças ocorrem em escala contínua, decorrentes de demandas situacionais internas e externas".

Nesse contexto surge a Liderança Situacional, uma ferramenta poderosa para suprir as necessidades das empresas, ideal para momentos de crise. Por isso o trabalho do líder é fundamental.

$\mathrm{O}$ que diferencia este tipo de liderança das demais são as habilidades do líder em identificar o perfil do liderado, considerando o seu desempenho atual nas atividades desenvolvidas, não pela pessoa humana que é ou no seu potencial, e ter conhecimento sobre os diversos perfis de liderança para usá-los, um ou outro, nos momentos mais oportunos. A receptividade, porém, de suas estratégias pelos liderados, vai depender do nível de maturidade destes e como se prontificarão a receber este modelo de liderança.

Nesse sentido, buscamos aprofundar os conceitos de líder e liderança, sendo que para melhor compreensão do tema fizemos uso de pesquisas bibliográficas, artigos científicos, monografias, sites especializados em liderança, todos de caráter exploratório, apresentando diversos conceitos, suas particularidades e objetivos. O estudo aqui apresentado tem por objetivo melhor compreender a importância da liderança situacional nas tomadas de decisão em qualquer organização, pois o sucesso e a manutenção dessas organizações no mercado competitivo dependem de líderes bem capacitados, do desempenho satisfatório de suas lideranças, de uma gestão realizada com material humano de qualidade, de decisões tomadas no momento certo e com a precisão e rapidez que o mercado exige.

\section{Líder, Liderança e Liderar}

Chiavenato (2004, p.100) ressalta que a liderança é necessária em todos os tipos de organização humana, seja nas empresas, seja em cada um de seus departamentos. Em toda organização, a liderança é apenas uma das funções de qualquer gerente; as outras passam 
pelo planejamento de ações e direcionamentos a serem tomados, organização e criação de processos, além, obviamente, por fazê-los funcionar e controlar para que os resultados almejados sejam alcançados. Nessa perspectiva, liderar é contribuir com a equipe para que todos visualizem a direção a seguir, é motivar e entusiasmar cada liderado para o empenho e comprometimento diante de suas obrigações e responsabilidades.

Para Bennis (1996, p.78), “a presença do líder é importante para a eficácia das organizações, para as frequentes turbulências e mudanças do ambiente e para a integridade das instituições". Em um ambiente de profunda e constante transformação em que vivem as organizações, é fundamental a presença de uma liderança, pois é a força que incentiva que direciona e que torna possível o desenvolvimento e a permanência das organizações nesse cenário.

De acordo com Lopes et al. (2008, p.4),

as características de um líder são sua energia e tenacidade em enfrentar desafios, confiança em suas habilidades, criatividade, conhecimento do negócio onde atua, facilidade em identificar comportamentos e interpretar as informações que recebe continuamente, flexibilidade para mudar com facilidade e principalmente ética, integridade e honestidade.

Peter Drucker (1996, p.11), na introdução do livro O Líder do Futuro, ressalta algumas características que observou nos líderes em suas pesquisas, a saber:

(i) “O líder é alguém capaz de fazer com que os outros o siga, sendo principalmente este o tipo de habilidade que melhor o descreve.", (ii) "O líder eficaz não é alguém que se adore ou se admire. Seus colaboradores fazem aquilo que convém a eles fazer. A qualidade da liderança não se mede pela popularidade que gozam, mas pelos resultados que ele consegue produzir.", (iii) "Os líderes estão em grande evidência. É por isso que conseguem dar exemplo.", e (iv) "A liderança não é uma questão de classificação, de privilégios, de títulos ou de dinheiro. É uma questão de responsabilidade."

Os desafios que um líder enfrenta são inúmeros e complexos. Todo líder deve estar em constante atividade mental na elaboração de estratégias a fim de que seus lideradosdeem o máximo de si. O líder deve sempre inovar e ser pioneiro nos processos de mudança, buscando e experimentando novos rumos, estimulando a inovação por parte dos colaboradores e apoiando-os para que tragam boas ideias à organização.

O líder deve ser desafiado a demonstrar bom ânimo às suas próprias atividades e realizações, às suas próprias conquistas. Ninguém deseja ser liderado por alguém a quem falte ousadia e autoconfiança. Essas características transmitem segurança a toda equipe. Um líder desanimado ou incapaz de reconhecer os avanços de suas equipes, que não inspira e não vibra com as conquistas rapidamente deixará de ser exemplo aos seus liderados. Conforme Silva e Kovaleski (2006, p.2),

[...] o fator chave na liderança situacional é a necessidade do líder desenvolver sua sensibilidade e percepção, diagnosticando sua equipe para que possa definir como irá se comportar, pois em qualquer situação em que uma equipe possa estar, a liderança sempre deverá realizar suas funções básicas de gerir com atenção concentrada nos objetivos e resultados.

Goffee e Jones (2005, p.78, apud NELSON; SANT'ANNA, 2010, p.310) afirmam, em tempo, que "o desafio da grande liderança é exatamente o de administrar a própria autenticidade, por mais paradoxal que isso soe". Segundo os autores, qualquer pessoa que exerça algum tipo de liderança deve buscar essa autenticidade ao longo de sua vida: "A menos que você conheça a si mesmo, suas forças e fraquezas, e saiba o que quer e por que o quer, não encontrará o verdadeiro sucesso" (BENNIS, 1996, p.39). O autor entende que esse conhecimento é oriundo, sobretudo, da reflexão sobre suas experiências pessoais, num diálogo socrático sobre o que aconteceu, por que e o que representou para si. O líder eficaz precisa tomar conhecimento de quem ele é, através do autoconhecimento a partir de reflexões profundas das experiências e questionamentos. "Assim, o líder começa por estruturar-se, inspirando-se a si mesmo, confiando em si mesmo, e acaba inspirando aos outros e despertando a confiança" (BENNIS, 1996, p.55).

É importante que o líder identifique e desenvolva habilidades em seus liderados, incentivando e buscando analisar em que setores cada um pode desempenhar suas atividades com maior eficiência. Um líder bem preparado é capaz de reconhecer novos talentos. É comum que gestores com pouca experiência acreditem que qualquer pessoa pode ocupar determinados cargos ou exercer 
certas funções. Um equívoco. Todos apresentam particularidades para o melhor desempenho de suas funções sob certas condições ou em ambientes específicos.

Outra função importante do líder moderno é reconhecer as redes de relacionamentos entre os membros de suas equipes e fazer uso desses contatos. O líder deve ser habilidoso o suficiente para extrair esse tipo de informação. Quanto mais se conhece as pessoas com as quais trabalha, maiores as chances de aumentar a produtividade e a qualidade dos processos, produtos e serviços. O exercício da liderança hoje em dia exige um relacionamento humano mais afetuoso. A criação em seus colaboradores de um senso de equipe e de relações mais próximas, além das profissionais, também faz parte das obrigações de todo líder, de modo que se unam harmoniosamente em redes de relacionamento e de cooperações mútuas, sem deixar de estimular, todavia, uma disputa sadia na busca por novos patamares de excelência em toda a organização. Conforme Lewin apud Gronkoski (2007, p.6), “a liderança é o determinante decisivo da atmosfera do grupo, ou seja, do clima organizacional".

Para Blanchard et al. (2007, p.15), a liderança é a "capacidade de influenciar os outros a liberar seu poder e potencial de forma a impactar o bem maior". Esta definição se relaciona à observação de que a liderança não se refere tão somente a resultados, pois " [...] não deve ser exercida apenas por um ganho pessoal ou para atingir objetivos, deve ser um propósito muito maior" (BLANCHARD et al., 2007, p.16). Para os autores, este objetivo maior denomina-se visão arrebatadora, ou melhor, uma organização que está em conformidade com sua missão, visão, propósitos, valores e credibilidade, tanto de seus colaboradores quanto de seus clientes.

Mas definir e estudar liderança não são tarefas fáceis. Há muito tempo o ser humano vem tentando compreender o fenômeno da liderança. Inúmeras abordagens e estudos procuram explicar a liderança e apontar formas de desenvolvê-la. Essa definição sofre profundas transformações no decorrer do tempo e conforme a cultura analisada, sujeitando-se, contudo, a uma infinidade de tendências e estilos. Para cada abordagem constata-se um novo conceito de liderança. Segundo Burns (1978, apud NELSON; SANT'ANNA, 2010, p.147), "a liderança é um fenômeno muito estudado e pouco compreendido", apesar de estar sempre presente em quase toda literatura sobre comportamento organizacional. "Embora estudos recentes estejam propondo novas formas de se analisar a liderança, é ainda evidente a ausência de abordagens mais amplas e integradoras, capazes de examinar o fenômeno em suas várias facetas" (YUKL, 2002 apud NELSON; SANT'ANNA, 2010, p.148).

Vale destacar que, para Davis e Newstrom (1992, p.150), "sem liderança, uma organização seria um1a confusão de pessoas e máquinas, do mesmo modo que uma orquestra sem maestro seria somente músicos e instrumentos. A orquestra e todas as outras organizações requerem liderança para desenvolver ao máximo seus preciosos ativos".

Para Lacombe (2009, p.204),

o líder empresarial deve ser capaz de alcançar objetivos por meio dos liderados e, para isso, conforme o tipo de liderado e a ocasião, age de diferentes maneiras: ele ordena, comanda, motiva, persuade, dá exemplos pessoais, compartilha os problemas e ações ou delega e cobra resultados, alterando a forma de agir de acordo com a necessidade de cada momento e com o tipo de liderado, visando a alcançar os objetivos da empresa.

Soto (2002, p.216) reforça que,

"liderança é um processo de influência nos demais para que trabalhem com entusiasmo para cumprirem seus objetivos. É o fator decisivo que ajuda as pessoas ou grupos a descobrirem as suas metas e que depois as motiva no cumprimento dos propósitos estabelecidos".

Vale a pena destacar que, para Davis e Newstrom (1992, p.150), "sem liderança, uma organização seria uma confusão de pessoas e máquinas, do mesmo modo que uma orquestra sem maestro seria somente músicos e instrumentos. A orquestra e todas as outras organizações requerem liderança para desenvolver ao máximo seus preciosos ativos".

Através dessa habilidade em observar cada situação e adotar os métodos que julga mais adequado, conforme cada caso, orientando seus liderados, o líder acaba exercendo o que se denomina liderança situacional.

\section{Liderança situacional: Descrição do modelo de Hersey e Blanchard}

O líder deve procurar conhecer mais de perto o perfil de cada liderado, conhecendo-os na forma de pensar e agir, buscando 
compreender o comportamento de cada membro da equipe para potencializar as capacidades de cada um, sempre com o objetivo de alcançar os resultados esperados pela organização. Todavia, não existe um estilo único de liderança que se adeque a todas as situações. Conforme Chiavenato (2004, p.105), "as teorias situacionais explicam a liderança dentro de um contexto mais amplo e partem do princípio de que não existe um único estilo de liderança válido para toda e qualquer situação". Porém, o modelo de liderança influencia a forma como as tarefas serão desempenhadas. E a figura do líder é fundamental no processo de gestão de pessoas e na busca por resultados satisfatórios. É o líder quem se encarrega de dirigir as pessoas, definindo as funções de cada subordinado e objetivos a serem atingidos. Dentre os vários modelos de liderança e formas de liderar, abordaremos a Liderança Situacional.

Paul Hersey e Kenneth Blanchard, pesquisadores do Center ofLeadershipStudies, Califórnia, EUA, desenvolveram o modelo da Liderança Situacional baseados em observações quanto à eficácia dos estilos de liderança, o qual parte da premissa de que a liderança eficaz é uma função que envolve três variáveis: o estilo do líder, a maturidade do liderado e a situação encontrada. É uma metodologia que oferece aos líderes uma melhor compreensão da relação entre liderança eficaz e o nível de maturidade dos colaboradores. É um modelo que estabelece uma relação entre liderança, motivação e poder, onde o líder avalia continuamente o desempenho de seus colaboradores e busca necessariamente adequar-se ao momento, alterando o seu estilo. E dentro dessa dinâmica e flexibilidade consegue delegar e motivar seus liderados para que reajam positivamente, dêem o máximo de si e alcancem os resultados desejados. É uma liderança moldada pela situação apresentada. Por isso, a forma de gestão de um líder situacional é diferenciada. A principal diferença desse modelo para os demais é a habilidade do líder em diagnosticar o liderado, conhecendo o desempenho atual do seu colaborador e aplicando estilos distintos para cada situação vivida.

Hersey e Blanchard (1986), Schermerhorn et al.(1999) e Robbins (2002) salientam que é essencial a análise dos fatores situacionais para o líder agir de forma eficaz. $\mathrm{O}$ problema passa a ser, a partir daí, descobrir o estilo mais eficaz para cada situação, em vez de descobrir o melhor estilo. Isso se deveu ao questionamento sobre qual o melhor estilo de liderança.

"Na liderança situacional está implícita a ideia de que o líder deve ajudar os liderados a amadurecerem até o ponto em que sejam capazes e estejam dispostos a fazê-lo" (SPRICIGO, 1999, p.48 apud SILVA; KOVALESHI, 2006, p.2). É essencial destacarmos aqui que o grau de maturidade dos subordinados é em relação ao desempenho de suas funções, e não em relação à sua personalidade. Para Hersey e Blanchard (1986, p.187), "maturidade é a capacidade e a disposição das pessoas de assumirem a responsabilidade de dirigirem seu próprio comportamento", adequando-se à situação e gerindo seu trabalho de forma efetiva, sem a necessidade da interferência direta do líder. Ainda, segundo os autores, essa maturidade divide-se em duas componentes: maturidade de trabalho (capacidade) e a maturidade psicológica (motivação).

$\mathrm{Na}$ definição acima, a variável capacidade refere-se ao conhecimento, à compreensão e à habilidade técnica, é o saber o que fazer e o como fazer. As pessoas com elevada maturidade numa determinada área do conhecimento têm experiência e capacidade suficientes para a execução de certas tarefas sem a intervenção do líder. Esse tipo de maturidade é avaliado em quatro categorias: pouca maturidade, alguma maturidade, bastante maturidade e muita maturidade. Para exemplificarmos, uma pessoa com alta maturidade de trabalho poderia dizer: "O conhecimento que eu tenho me permite desempenhar minhas tarefas por conta própria nessa área, sem precisar da ajuda do meu chefe".

Já a disposição está relacionada à motivação, é o querer fazer, é a autoconfiança, o empenho pessoal na tarefa, é a realização como ser humano. As pessoas com alta maturidade psicológica julgam ser importante a responsabilidade, são autoconfiantes e se sentem bem nesse aspecto do trabalho. Não precisam de muito incentivo para cumprirem com suas obrigações.

Os critérios sobre o nível de maturidade (capacidade + disposição) do liderado são avaliados pelo líder, o qual busca conhecer se o subordinado possui experiência e formação para o desempenho das tarefas. Ao alcançar o nível desejado, o colaborador aumenta sua produtividade e passa a lidar melhor com as mudanças, é capaz de inovar e apresentar 
resultados positivos mesmo diante às adversidades. Do contrário, deverá o líder monitorar todas as atividades, motivar continuamente e apoiá-lo na construção dos resultados, pois o colaborador ainda não é capaz de adequar-se com autonomia às novas situações e às demandas imprevistas.

Segundo Hersey e Blanchard (1986), o nível de maturidade dos colaboradores assume quatro estágios distintos: M1 (baixa): pessoas que demonstram baixa capacidade de execução de tarefas e pouca vontade de assumirem responsabilidades (baixa capacidade e motivação); M2 (baixa a moderada): pessoas ainda com certa deficiência na capacidade de execução, mas que demonstram boa vontade. Têm motivação, mas ainda carecem de certas competências para realizarem as tarefas e assumirem um nível mais elevado de responsabilidades (baixa capacidade e alta motivação); M3 (moderada a alta): pessoas com bastante capacidade de execução de tarefas, mas com certa instabilidade no grau de motivação, nem sempre atendendo com boa vontade às solicitações do líder (alta capacidade e baixa motivação); M4 (alta): pessoas com elevada capacidade e competência para a realização de tarefas e com muita vontade de cumprir suas responsabilidades (alta capacidade e motivação). Para os autores, esses estágios distintos de maturidade, sob a influência da liderança situacional, interferem nas formas de pensar e agir do líder para alcançar o sucesso na gestão de pessoas. A figura 01 ilustra os níveis de maturidade dos liderados.

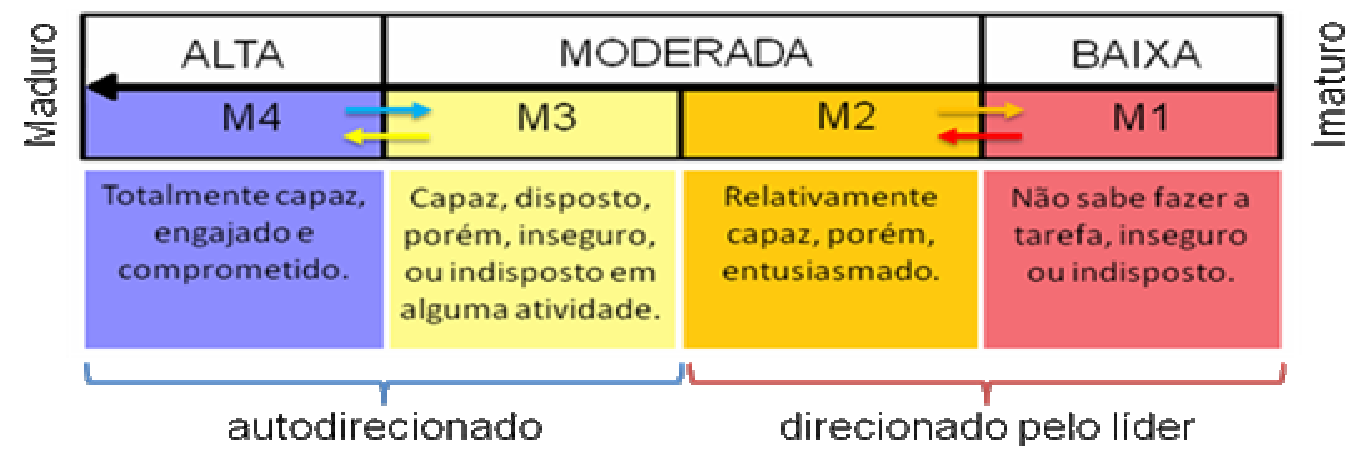

Figura 1: Maturidade dos liderados

Fonte: HERSEY; BLANCHARD, 1986

Vale reforçar que cada estilo de liderança é uma combinação de comportamentos de tarefa (aspectos da produção) e de relacionamento (aspectos do indivíduo). O comportamento de tarefa está relacionado à estrutura de trabalho e, assim, quanto maior o comportamento de tarefa, mais o líder deverá se empenhar em planejar, controlar, organizar e dirigir seus liderados. Em contrapartida, quanto mais baixo o comportamento de tarefa, mais o líder delega as atividades aos colaboradores. Sobre o comportamento de relacionamento, a questão é o apoio dispensado ao liderado. Quanto maior o comportamento de relacionamento, mais o líder deve se empenhar em oferecer apoio sócio-emocional e canais de comunicação, o que significa ouvir de forma efetiva, estimular e apoiar os esforços dos liderados.

Os níveis de maturidade podem ser aplicados tanto a indivíduos quanto a equipes. O líder que trabalha com alguma equipe não só pode como deve determinar sua maturidade através da observação de predominâncias individuais. No propósito de adequar o estilo do líder ao grau de maturidade do liderado, os autores advertem que, no processo de identificação do grau de maturidade, "essas variáveis devem ser consideradas somente em relação a uma tarefa específica a ser realizada" (HERSEY; BLANCHARD, 1986, p.187). Isso significa que uma pessoa ou equipe não é absolutamente madura ou imatura, porém, que ela é relativamente madura para aquela tarefa específica, função ou objetivo. Dependendo da atribuição, cada colaborador ou equipe pode assumir diferentes níveis de capacidade e disposição.

Hersey e Blanchard (1986) afirmam que, para fazer frente aos diversos tipos de maturidade, o líder eficaz deve utilizar diferentes estilos de liderança, os quais devem ser aplicados de acordo com o nível de maturidade do liderado. E o estilo de liderança em cada nível de maturidade inclui a dosagem certa de comportamento de tarefa (diretivo) e comportamento de relacionamento (motivacional).

Segundo os autores, o estilo Direcionar ou Determinar (E1) é adequado para a baixa 
maturidade (M1), pois os que se encontram nesse nível geralmente são "pessoas que não têm capacidade nem vontade de assumir a responsabilidade de fazer algo, não são competentes, nem seguras de si" (HERSEY; BLANCHARD, 1986, p.190). Os autores deixam claro que essa classificação de maturidade baixa pode se dever pela insegurança da pessoa em exercer a atividade a ela conferida. Se assim for, o estilo Determinar tem maiores chances de eficácia por ser um estilo mais diretivo, de supervisão clara e bem definida. O líder define as funções e especifica o que, como, quando e onde as pessoas devem fazer as tarefas.

Sobre o estilo Treinar ou Persuadir (E2), Hersey e Blanchard (1986) apontam para a maturidade baixa a moderada (M2). Nesse grau de maturidade, o liderado não tem capacidade, mas sente-se disposto e confiante em si mesmo para assumir as responsabilidades. Assim, o estilo Persuadir é diretivo, como o estilo E1, porém, adota um comportamento de apoio para reforçar a disposição e o entusiasmo do liderado.

Quanto ao estilo Compartilhar ou Apoiar (E3), os autores indicam para a maturidade entre moderada e alta (M3). Segundo eles, as pessoas nesse nível possuem capacidade, mas não estão muito dispostas a executarem suas tarefas. Novamente soa um alerta para a possibilidade de essa indisposição ser devido à baixa confiança em sua própria capacidade. Esse estilo deve adotar, agora, um comportamento não mais diretivo, porém, de apoio aos liderados por meio de comunicação bilateral eficaz e escuta ativa. Dessa forma, tanto o líder como o liderado participam juntos da tomada de decisão e o líder tem um papel de facilitador.

Para Bergamini (1994, p.105 apud NAMIKI, 2000, p.2), "o líder tem o papel de facilitador, não é sempre que o líder se depara com uma equipe motivada. É preciso criar um ambiente propício no qual o trabalhador desperte o seu potencial motivacional". Segundo Chiavenato (2004, p. 455-457 apud DALMUTT, H. B; MOROZINI, J. F., 2008, p.10-11), "O líder funciona como um facilitador para orientar o grupo, ajudando-o na definição dos problemas e nas soluções coordenando atividades e sugerindo ideias".

Sobre o último estilo, o Delegar (E4), Hersey e Blanchard (1986) orientam que esse comportamento é mais indicado para o alto nível de maturidade (M4), pois, nessa fase, o liderado ou grupo tem competência e disposição para exercer suas responsabilidades. É um estilo baseado em pouco apoio e direção. O líder pode até identificar o problema, porém, deixa a cargo dos liderados a responsabilidade de execução dos planos, desenvolvendo o projeto e decidindo como, onde e quando realizar as atividades.

$\mathrm{Na}$ figura 02,temos uma representação dos quatro estilos de liderança e os quatro níveis de maturidade identificados pelos autores. Indicados por uma curva sinoidal prescritiva, esses estilos de liderança passam pelos quatro estágios: tarefa alta e relacionamento baixo (E1), tarefa alta e relacionamento alto (E2), tarefa baixa e relacionamento alto (E3), e tarefa baixa e relacionamento baixo (E4).

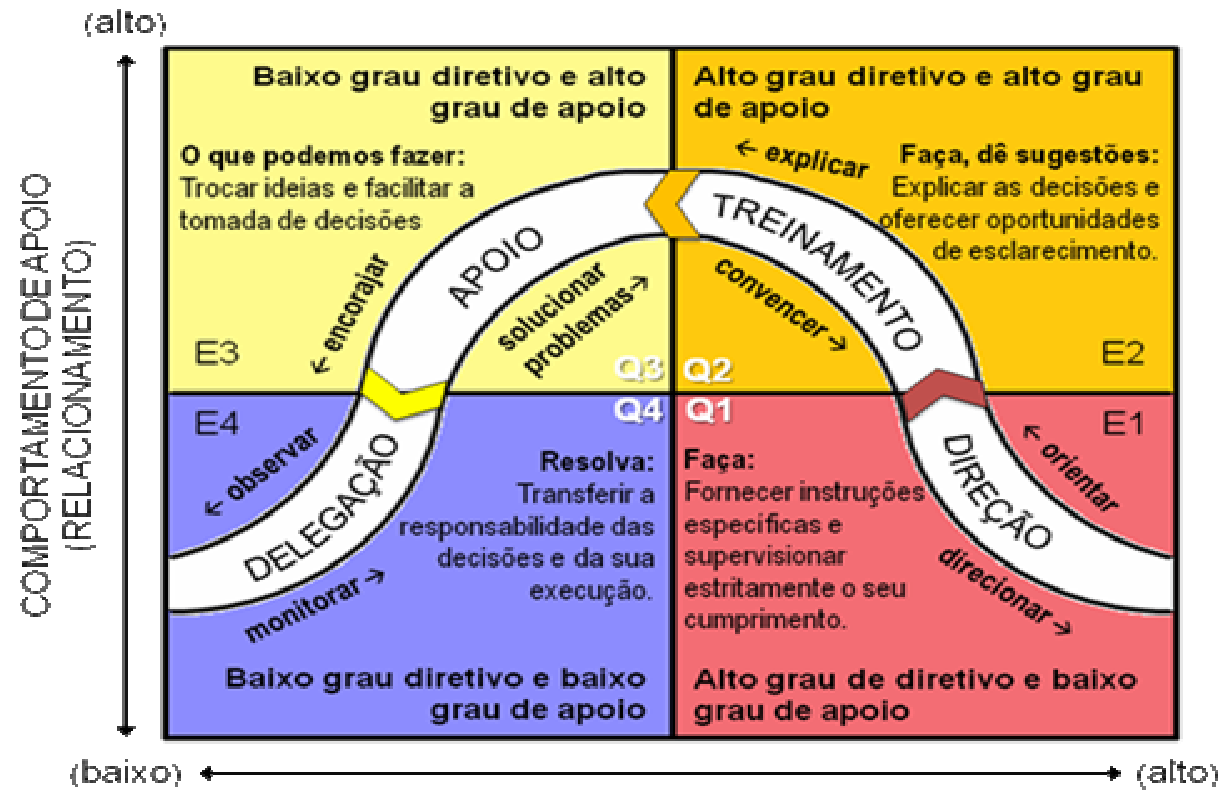

Figura 2: Comportamento do líder

Fonte: HERSEY; BLANCHARD, 1986. 
O quadro, figura 03, resume o estilo de liderança associado ao nível de maturidade do liderado.

\begin{tabular}{lll}
\hline E1 & Direção & $\begin{array}{l}\text { O líder fornece instruções } \\
\text { específicas e } \\
\text { rigorosamente o cumprimento das } \\
\text { tarefas. }\end{array}$ \\
\hline E2 & Treinamento & $\begin{array}{l}\text { O líder continua a dirigir e e } \\
\text { supervisionar atentamente a } \\
\text { realização de tarefas, mas explica } \\
\text { também decisões, solicita sugestões } \\
\text { e incentiva o desenvolvimento. }\end{array}$ \\
\hline E3 & Apoio & $\begin{array}{l}\text { O líder facilita e apoia os esforços } \\
\text { dos subordinados para cumprir } \\
\text { tarefas e compartilha com eles as } \\
\text { tomadas de decisões. }\end{array}$ \\
\hline E4 & Delegação & $\begin{array}{l}\text { O líder transfere a responsabilidade } \\
\text { do processo decisório e da solução } \\
\text { de problemas aos subordinados. }\end{array}$ \\
\hline
\end{tabular}

Figura 3: Características do estilo de liderança Fonte: HERSEY; BLANCHARD, 1986.
A Liderança Situacional parte da premissa de que sobre pessoas com pouca capacidade e disposição (M1) é preciso mais controle e estruturação das tarefas. Conforme a pessoa vai se capacitando (M2), o controle deverá ir diminuindo e o apoio socioemocional deverá ir aumentando. Quando a capacidade e a disposição se tornarem maiores (M3), o líder deverá diminuir ainda mais esse controle e, paralelamente, seu comportamento de relacionamento. Por fim, para as pessoas com alta maturidade (M4), já não é mais necessário o apoio socioemocional. São pessoas que prezam pela autonomia. Sentem-se satisfeitas quando as tarefas e as decisões são deixadas sob suas responsabilidades. A figura 04 analisa simultaneamente o nível de maturidade do liderado com o estilo de liderança.

\section{Modelo de Liderança Situacional}

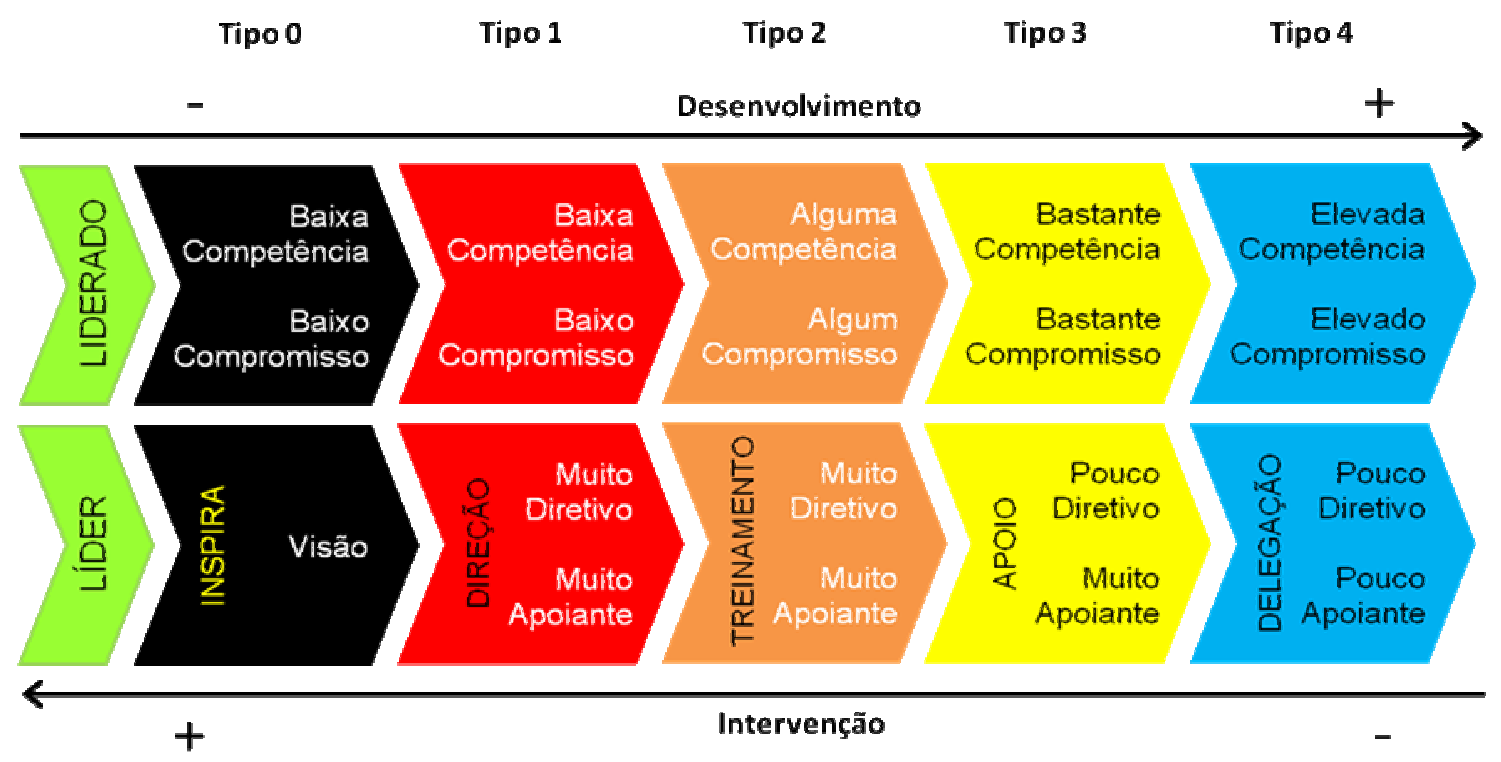

Figura 4: Modelo de Liderança Situacional

Fonte: HERSEY; BLANCHARD, 1986.

A capacidade do líder em diagnosticar uma situação antes de qualquer tomada de decisão e aplicar o estilo mais adequado àquela situação é fundamental para tornar-se um líder eficaz. Chiavenato (1997, p.710) define o processo de tomada de decisão como "o processo de análise e escolha entre várias alternativas disponíveis do curso de ação que a pessoa deverá seguir". Dessa forma, o autor aponta que o processo de decisão é complexo e está sujeito às características individuais do responsável a decidir, quanto da circunstância em que está envolvido e da maneira como compreende essa situação. Também é da competência do líder ajudar os liderados a amadurecerem, além de ficar atento caso ocorra alguma situação que possa regredir o grau de maturidade. Se assim ocorrer, os autores aconselham o líder a reavaliar o nível de maturidade dos envolvidos e, se necessário, adequar novamente o estilo de liderança. Para Hersey e Blanchard (1986, p.117), "os líderes eficazes são capazes de adaptar seu estilo de comportamento às necessidades dos liderados e à situação, sendo estas não constantes, o uso do estilo apropriado de comportamento líder constitui um desafio para cada líder eficaz". 
Os estilos de liderança (direção, treinamento, apoio e delegação) são uma combinação de tarefa e de relacionamento. $\mathrm{O}$ comportamento a ser adotado pelo líder deverá ser função do nível de maturidade das pessoas que deseja influenciar.

A representação abaixo descreve o estilo que o líder deve empregar em cada nível de maturidade. Sendo assim, cabe ao líder ajudar seus subordinados a amadurecerem, até $\mathrm{o}$ ponto em que sejam capazes e estejam dispostos a fazê-lo.
Os autores salientam que "o fato de um líder adotar um comportamento de tarefa alto e baixo de relacionamento não significa que sua relação com o liderado será pautada por um clima de animosidade, mas sim que o líder dedicará mais tempo direcionando o liderado do que lhe oferecendo apoio socioemocional". (HERSEY; BLANCHARD, 1986, p.78).

$\mathrm{O}$ quadro a seguir, figura 05 , esclarece com maiores detalhes a relação entre os níveis de maturidade dos subordinados e os estilos de liderança.

\section{NÍVEL DE MATURIDADE \\ $M_{1}$ Maturidade baixa: Considera que a pessoa não tem capacidade nem vontade de assumir a responsabilidade de fazer algo; não é competente nem segura de si, sendo em muitos casos, sua falta de disposição consequência da insegurança em relação à tarefa exigida.}

\section{ESTILO DE LIDERANÇA}

$\mathbf{E}_{1}$ Direção ou Determinar: Para pessoas que não têm nem capacidade nem vontade $\left(\mathbf{M}_{1}\right)$ de assumir a responsabilidade de fazer os padrões. Consequentemente, um estilo diretivo $\left(\mathrm{E}_{1}\right)$ que dá uma orientação e supervisão clara e específica é a mais apropriada. Para estas pessoas, o supervisor deve especificar o que elas devem fazer, como, quando e onde devem executar as várias tarefas. Os padrões devem ser entregues prontos.

$\mathbf{E}_{2}$ Treinamento: É o estilo a ser adotado para pessoas que sentem disposição, mas não têm capacidade. Ainda deve adotar-se um comportamento diretivo (especificar o que as pessoas devem fazer, como, quando e onde devem executar várias tarefas) por causa da falta de capacidade, mas ao mesmo tempo reforçar a disposição e o entusiasmo das pessoas. O líder procura conseguir que os liderados se sintam convencidos a adotarem os padrões e comportamentos desejados. Os operadores nesse nível de maturidade geralmente aceitam os padrões quando entendem as razões do mesmo e o supervisor lhes fornece a direção.

$\mathbf{M}_{3}$ Maturidade moderada a alta: Considera que a pessoa tem capacidade, mas não está disposta a fazer o que dela se espera. Sua falta de disposição, muitas vezes, é consequência da falta de confiança em si mesma ou insegurança. Entretanto, se for competente, mas pouco disposta, sua relutância em fazer o que dela se espera é mais uma questão de motivação do que um problema de insegurança.

$\mathbf{M}_{4}$ Maturidade alta: Considera que a pessoa neste nível tem capacidade e disposição para assumir responsabilidades.
$\mathbf{E}_{3}$ Apoio ou participativo: Para maturidade entre moderada e alta. As pessoas neste nível de maturidade têm capacidade, mas não estão muito dispostas a elaborar os padrões. Neste caso, o supervisor precisa abrir a porta no sentido de apoiar os operadores nos seus esforços de utilizarem a capacidade que já possuem e passem a elaborar os seus próprios padrões que determinam como, quando e onde fazer as coisas.

$\mathbf{E}_{4}$ Delegar: As pessoas neste nível de maturidade têm capacidade e disposição para elaborar padrões, embora possa ser o supervisor quem ainda determina quais são os padrões a serem elaborados; a responsabilidade de fazê-los já é dessas pessoas.

Figura 5: Estilo do líder em função do grau de maturidade do liderado.

Fonte: HERSEY e BLANCHARD, 1986.

A liderança situacional defende a necessidade de uma direção rígida para que as tarefas sejam desempenhadas de forma produtiva por parte dos liderados que ainda não apresentam o grau de maturidade desejado. Quanto maior o nível de maturidade dos liderados menor será o controle dos líderes sobre suas atividades, menor será o apoio no comportamento de relacionamento, pois equipes formadas por pessoas maduras necessitam cada vez mais de autonomia. Para Cavalcanti (2002, p.34), “a Liderança
Situacional criada por Hersey e Blanchard (1986) objetiva levar os indivíduos ao seu mais elevado nível de desempenho através da liderança eficaz de um a um", buscando combinar o nível de desenvolvimento de uma pessoa (várias combinações de competência e comprometimento) para se atingir um objetivo específico ou a realização de uma tarefa e o estilo de liderança (várias combinações de comportamento diretivo e motivacional).

Outro ponto a se destacar é a questão da confiança, visto que quanto mais madura for a 
equipe, mais podemos deixá-la à vontade no exercício de suas funções. Não que inexista confiança mútua entre líder e liderado em função da maturidade. O que ocorre é que quanto maior for esse nível, menor é a interferência de apoio nas equipes, menos monitoramento o líder deverá realizar para provar sua confiança. Porém, independente do nível de maturidade de qualquer liderado ou grupo, mudanças podem ocorrer. Por qualquer razão, se o desempenho de um colaborador ou grupo começar a regredir na produtividade, na capacidade, ou mesmo na motivação, o líder deverá reavaliar esse grau de maturidade no propósito de adequar seu apoio segundo o comportamento

de

relacionamento

apresentado.

Hersey e Blanchard (1986) apontam para a necessidade de acrescentar mais um fator a este modelo: a eficácia. $\mathrm{O}$ estilo de comportamento seria integrado, desse modo, aos requisitos situacionais de um ambiente. $\mathrm{O}$ estilo eficaz seria aquele adaptado à situação específica. $O$ quadro a seguir (figura 06) apresenta cada estilo que se aplica às situações nas quais é apropriado e nas quais não é apropriado, resultando em sua eficácia ou ineficácia. Um dos pontos que condicionam a eficácia do comportamento do líder refere-se à maturidade do liderado.

\begin{tabular}{|c|c|c|}
\hline ESTILO & EFICÁCIA & INEFICÁCIA \\
\hline $\begin{array}{l}\text { Tarefa Alta } \\
\text { Relacionamento } \\
\text { Baixo }\end{array}$ & $\begin{array}{l}\text { Visto como tendo métodos bem definidos para } \\
\text { atingir os objetivos que são úteis aos } \\
\text { subordinados. }\end{array}$ & $\begin{array}{l}\text { Visto como alguém que impõe métodos aos } \\
\text { outros; às vezes visto como desagradável e } \\
\text { interessado apenas em resultados de curto prazo. }\end{array}$ \\
\hline $\begin{array}{l}\text { Tarefa Alta } \\
\text { Relacionamento } \\
\text { Alto }\end{array}$ & $\begin{array}{l}\text { Visto como alguém que satisfaz às necessidades } \\
\text { do grupo estabelecendo objetivos e organizando } \\
\text { o trabalho, mas também oferecendo um alto nível } \\
\text { de apoio socioemocional. }\end{array}$ & $\begin{array}{l}\text { Visto como alguém que usa mais estruturação do } \\
\text { que o necessário para o grupo e que muitas vezes } \\
\text { não parece ser sincero nas relações interpessoais. }\end{array}$ \\
\hline $\begin{array}{l}\text { Tarefa Baixa } \\
\text { Relacionamento } \\
\text { Alto }\end{array}$ & $\begin{array}{l}\text { Visto como alguém que tem confiança implícita } \\
\text { nas pessoas e que está interessado principalmente } \\
\text { em facilitar a consecução dos objetivos delas. }\end{array}$ & $\begin{array}{l}\text { Visto como interessado principalmente em } \\
\text { harmonia; às vezes visto como não disposto a } \\
\text { cumprir uma tarefa se esta implicar no risco de } \\
\text { romper um relacionamento ou perder a imagem } \\
\text { de uma pessoa boa. }\end{array}$ \\
\hline $\begin{array}{l}\text { Tarefa Baixa } \\
\text { Relacionamento } \\
\text { Baixo }\end{array}$ & $\begin{array}{l}\text { Visto como alguém que delega adequadamente } \\
\text { aos subordinados as decisões sobre como fazer o } \\
\text { trabalho e oferece pouco apoio sócioemocional } \\
\text { quando o grupo não precisa muito disso. }\end{array}$ & $\begin{array}{l}\text { Visto como alguém que oferece pouca } \\
\text { estruturação ou apoio socioemocional quando } \\
\text { isso é necessário aos membros do grupo. }\end{array}$ \\
\hline
\end{tabular}

Figura 6: A eficácia na liderança

Fonte: HERSEY; BLANCHARD, 1986.

Hersey e Blanchard (1986) distinguem os estilos de liderança dos quatro quadrantes, ressaltando que cada estilo de liderança deve ser empregado sobre um nível específico de maturidade, baseado na maior probabilidade de se obter os resultados desejados. Tal abordagem relaciona-se à necessidade efetiva do líder em empregar o estilo mais apropriado sob pena de exercer uma liderança ineficaz. Vamos entender melhor através de dois exemplos extremos:

1) Para o nível de baixo desempenho (M1), o estilo mais adequado é o diretivo (E1); do contrário, empregando-se o estilo de delegação (E4), por exemplo, a liderança será ineficaz.

2) Para o nível de alto desempenho (M4), o estilo mais adequado é o de delegar (E4); do contrário, com o estilo de direção (E1), por exemplo, a liderança também será ineficaz.

De acordo com Covey (2002, p.17, apud
MERCHO et al., 2007, p.7), “O poder é a capacidade de agir, a força e coragem para conseguir algo. É a energia vital para fazer escolhas e tomar decisões. Representa também a capacidade de ultrapassar hábitos profundamente incrustados e cultivar outros mais elevados e eficazes."

\section{Considerações finais}

Em suma, ressaltamos que o papel do líder e sua forma de liderança são fundamentais para que uma organização consiga sobreviver e alçar maiores vôos no mercado altamente competitivo no mundo moderno. O capital humano é o maior bem de uma organização. É necessário capacitar novos líderes, investir em cada colaborador, criar um ambiente cada vez mais saudável nas organizações para que todos se sintam motivados a desenvolverem suas atividades da forma mais eficaz possível.

A liderança situacional, quando bem desempenhada, permite aos líderes enxergarem 
o grau de maturidade de cada liderado, permite a autonomia de cada colaborador no exercício de suas funções, consegue motivar suas equipes de forma mais eficiente, aproxima os líderes de suas equipes, aumenta e aperfeiçoa a comunicação entre todos na organização. Enfim, as decisões que porventura o líder tiver que tomar no exercício desse modelo de liderança serão mais seguras, precisas e eficientes, tanto para o bem estar dos colaboradores como para a própria organização, de modo geral.

Tomar decisões exige, tanto dos gestores quanto dos líderes, análises eficientes e eficazes no dia-a-dia profissional. Cenários distintos e complexos, além das situações de conflito no mundo corporativo e dos negócios, remetem aos gestores e líderes a responsabilidade em diagnosticar as melhores práticas, soluções e alternativas para o processo decisório.

As organizações se encontram atualmente em um ambiente de enorme complexidade, imprevisível, dinâmico e disforme, e a presença de líderes cada vez mais eficazes e flexíveis diante de tamanha volatilidade é fundamental para que as organizações continuem sobrevivendo e mantenham a competitividade em meio às situações apresentadas. A Liderança Situacional salienta a necessidade de os líderes adaptarem seus perfis de liderança para atuações cada vez mais eficazes aos distintos cenários no ambiente organizacional.

Além dessas importantes variações de cenários, a Liderança Situacional destaca com bastante propriedade a necessidade de o líder adaptar seu próprio estilo ao do liderado, necessidade esta que as teorias anteriores raramente faziam e, quando faziam, não davam a devida importância. Inúmeros e renomados autores consideram essenciais as características dos liderados para a legitimação da liderança.

Com toda a complexidade dos cenários, o líder precisa, ainda, lidar com a complexidade do ser humano, o qual é movido por desejos e objetivos os mais variados, os quais também se modificam conforme as contingências de cada momento. A Liderança Situacional considera vital a análise desses aspectos intrínsecos à natureza humana para o exercício da liderança.

Dessa forma, a Liderança Situacional trata da necessidade de uma contínua preocupação com o planejamento de novas estratégias a serem adotadas pelo líder, levando em conta não apenas as variáveis situacionais, mas especialmente as humanas, pois o modelo parte do princípio que o liderado deve estar preparado para as mudanças antes de qualquer implantação.

Podemos concluir que as limitações e dificuldades para a implantação dessa teoria são muitas, mas o valor que as contribuições da teoria de Hersey e Blanchard trazem para o processo de gestão organizacional especialmente no que se refere à flexibilidade dos conceitos e da aplicação, além do foco no liderado, ambos aspectos de suma importância formando a base de atuação do líder - é inestimável frente aos desafios que são impostos a toda a organização no mundo moderno.

\section{Referências}

ANDRADE, R. J. F.; et al. Contribuições da liderança situacional para as organizações. In: VI CONGRESSO NACIONAL DE EXCELÊNCIA EM GESTÃO. 2010, Niterói. Anais... Niterói, Rio de Janeiro: Energia, Inovação, Tecnologia e Complexidade para a Gestão Sustentável, 2010.

BENNIS, W. G. A formação do líder. Tradução de Marcelo Levy. São Paulo: Atlas, 1996.

BLANCHARD, K. et al.. Liderança de alto nível: como criar e liderar organizações de alto desempenho. Tradução de Rosália Neuman Garcia. Porto Alegre: Bookman, 2007.

CAVALCANTI, V. L. Desenvolvimento de Equipes Estratégicas. Rio de Janeiro: Cursos de Educação Continuada. 2002.

CHIAVENATO, I. Introdução à Teoria da Administração. 5. ed. São Paulo: Makron Books, 1997.

.Iniciação à administração geral. 3. ed. São Paulo: Makron Books, 2000.

.Introdução à teoria geral da administração. Ed. Compacta. Rio de Janeiro: Elsevier, 2004.

DALMUTT, H. B.; MOROZINI, J. F. A Influência da Liderança na Gestão das Empresas do Município de Mangueirinha, Paraná. Revista Eletrônica Latu Sensu. Ano 3, n $\mathrm{n}^{\mathrm{o}}$., pp.1-25. Paraná. Publicado em: mar. 2008. Disponível em: <http://web03.unicentro.br/especializacao/Revista Pos/P\%C3\%A1ginas/3\%20Edi\%C3\%A7\% 3\%A3o/Aplicadas/PDF/13-Ed3_CS-

EstilosLide.pdf>. Acesso em: 10 mar 2014.

DAVIS, K.; NEWSTRON, J. W. Comportamento humano no trabalho. São Paulo: Pioneira, 1992.

DRUCKER, P. F. Administrando para o futuro: 
os anos 90 e a virada do século. Tradução de Nivaldo Montigelli Júnior. São Paulo: Pioneira, 1996.

A nova sociedade das organizações. In: HOWARD, R. (Org.) Aprendizado organizacional. Rio de Janeiro: Campus, 2000.

GRONKOSKI, M. Estilos de Liderança: estudo de caso em uma filial de uma empresa do comércio varejista. 2007, 25 f. Trabalho de Conclusão de curso ( Especialização em Gestão de Recursos Humanos) Universidade Estadual do Centro Oeste Unicentro, Paraná, 2007.

HERSEY, P; BLANCHARD, K. H. Psicologia para administradores de empresas: a utilização de recursos humanos. São Paulo: EPU, 1976.

Psicologia para administradores: a teoria e as técnicas da liderança situacional. São Paulo: EPU, 1986.

LACOMBE, F. Recursos humanos: princípios e tendências. São Paulo: Saraiva, 2009.

LOPES, A. O. et al.. O papel da liderança no ato de gerenciar pessoas com sucesso. Revista Científica Eletrônica de Administração, ano VIII, n.14, p.4,jun. 2008 .

MERCHO, L. et al. Liderança e motivação e suas aplicações em empresas. Revista Cientifica Eletrônica de Administração. São Paulo. Ano VII, n.13. Publicado em dez. 2007. Disponível em:
<http://www.revista.inf.br/adm13/pages/artigos/AD M-edic13-anovii-art01.pdf> Acesso em: 08 fev. 2010.

NAMIKI, B. R. O. et al.. Liderança. Monografia curso organização sistemas e métodos. São Paulo: Faculdade Integrada Campos Salles, 2000.

NELSON, R. E.; SANT'ANNA, A. S. Liderança: entre a tradição, a modernidade e a pósmodernidade. Rio de janeiro: Elsevier, 2010.

ROBBINS, S. P. A Verdade Sobre Gerenciar Pessoas. São Paulo: Pearson Education, 2002.

ROCHA, E. P. Feedback 360': Uma ferramenta para o desenvolvimento pessoal e profissional. Campinas: Alínea, 2001.

SCHERMERHORN, J.R.; et al. Fundamentos de comportamento organizacional. Porto Alegre: Bookman, 1999.

SILVA, U. B.; KOVALESKI, J. L. Desenvolvimento de equipe através da liderança situacional e feedback $360^{\circ}$ : caso de uma equipe de manutenção da Copel Distribuição Centro-Sul. In: ENCONTRO NACIONAL DE ENGENHARIA DE PRODUÇÃO, 26, 2006, Fortaleza. Anais. Rio de Janeiro: ABEPRO, 2006.

SOTO, E. Comportamento Organizacional: o impacto das emoções. Tradução de Jean Pierre Marras. São Paulo: Pioneira Thomson Learning, 2002 